\title{
A HISTORICIDADE DA SEXUALIDADE E OS MOVIMENTOS SOCIAIS DOS HOMOSSEXUAIS PELA PROTEÇÃO E DEFESA DE SEUS DIREITOS E GARANTIAS FUNDAMENTAIS
}

\section{THE HISTORICITY OF SEXUALITY AND SOCIAL MOVEMENTS OF GAY FOR PROTECTION AND DEFENSE OF THEIR RIGHTS AND WARRANTIES FUNDAMENTAL}

\author{
${ }^{1}$ Renata Almeida Da Costa \\ ${ }^{2}$ Valquiria Palmira Cirolini Wendt
}

\section{RESUMO}

O texto visa analisar a historicidade envolvendo a sexualidade desde o contexto binário normal ou anormal, transitando pela homossexualidade e os gêneros sexuais (terceiro gênero). Destaca a busca pelo reconhecimento dos homossexuais através dos movimentos sociais realizados, principalmente no Século XX. Assim, descreve a conquista de inúmeros direitos através de mobilizações e pela publicização dos temas através dos grupos homossexuais organizados no Brasil que, direta ou indiretamente, pautaram a mídia, foram reconhecidos no judiciário e sensibilizaram o poder público. Sobretudo, que os movimentos sociais tendem a buscar cada vez mais a afirmação da identidade dos homossexuais pela proteção e defesa de seus direitos e garantias fundamentais.

Palavras-chave: Sexualidade, Gênero, Homossexuais, Movimentos sociais, Direitos

\begin{abstract}
The text analyzes the historicity involving sexuality since the binary context "normal /abnormal", moving through the homosexuality and sexual genres (third gender). Highlighting the quest for recognition of homosexuals through social movements performed, especially in the twentieth century. Thus describes the conquest of many rights through demonstrations and by publicizing the issues through the organized homosexual groups in Brazil that, directly or indirectly, guided media, were recognized in judicial and sensitized the government. Above all, that social movements tend to look increasingly to assert identity of homosexuals the protection and defense of their rights and guarantees.
\end{abstract}

\footnotetext{
${ }^{1}$ É Doutora em Direito pela UNISINOS. Rio Grande do Sul. RS, Basil. E-mail: indexlaw.ojs @ hotmail.com

${ }^{2}$ Mestrado em andamento em Direito pelo Centro Universitário La Salle - Canoas, UNILASALLE. Rio Grande do Sul. RS, Brasil.. E-mail: indexlaw.ojs@ hotmail.com
} 
Keywords: Sexuality, Genre, Homosexuals, Social movements, Rights

\section{INTRODUÇÃO}

A sexualidade não é uma categoria fixa, mas que contemporaneamente sofre uma constante transformação e vai além do corpo sexuado, do aspecto biológico. O comportamento das pessoas é influenciado por diversos fatores no decorrer dos tempos.

O corpo "bissexuado" nem sempre foi o "normal” e, segundo Nicholson (1999, p. 10), os estudos realizados por Thomas Laqueur sobre o corpo, desde os gregos até o século XVIII, descreviam o corpo como uma "unidade unissexuada", ou seja, de sexo único. O corpo feminino, por ter os órgãos menos desenvolvidos que os masculinos, era considerado uma versão inferior e invertida do masculino.

Neste período, embora o modelo do sexo único, era enfatizada a importância do papel do feminino no prazer sexual, especialmente no processo da reprodução. O orgasmo feminino e o prazer eram vistos como necessários para a fecundação bem-sucedida (WEEKS, 2000).

Entretanto, no século XIX surge a noção de corpo "bissexuado" a partir do modelo reprodutivo da mulher, que enfatizou a existência de dois corpos bem diferentes e, segundo Weeks (2000, p. 57), “este foi um momento crítico na reformulação das relações de gênero, porque sugeria a diferença absoluta de homens e mulheres: não mais um corpo parcialmente diferente, mas dois corpos singulares, o masculino e o feminino".

Mas esta distinção não é assim tão simples na atualidade e pesquisadores como Judith Butler (2003; 2010), refutam a ideia de corpo como algo dado ou natural, discutemse esse clássico discurso científico sobre a classificação macho/fêmea, tendo em vista pesquisas recentes demonstrarem que parte da população tem

variações cromossômicas que não se encaixam exatamente nos conjuntos de categorias XX-fêmea e XY-macho, um fato que a leva a sugerir que os binarismos sexo/gênero existentes são inadequados para descrever e categorizar corpos indeterminados (SALIH, 2012, p. 88).

Neste sentido, Butler (2003; 2010) vem tentando desconstruir essas categorias fixas que engendram as identidades de homens e mulheres em pilares estanques. A autora questiona como a construção de uma divisão ontológica dos gêneros - que pressupõe a 
continuação coerente entre sexo, gênero e sexualidade - é fundamental para a manutenção de um mundo

heterossexual e heterossexista ${ }^{1}$, que cria e ordena normas que exigem a inteligibilidade de gênero para que o indivíduo possa ter inteligibilidade social. A desconformidade entre essas categorias reserva às identidades ininteligíveis o status de sub-humanidade e o locus marginal em que ocupam os abjetos.

No mesmo pensar, Bento (2006) contextualiza, por assim dizer, contemporaneamente, o processo de produção do sujeito no âmbito do sistema binário "homem x mulher" - e da matriz heteronormativa ${ }^{2}$. Ou seja, as normas de gênero, através de diversas tecnologias, estão cotidianamente trabalhando para que corpos-machos e corpos-fêmeas sejam constituídos. Este processo se inicia no período gestacional, momento em que já existe uma grande preocupação em se saber se o bebê é "menino" ou "menina" e, a partir do resultado do exame de ultrassom, todo o enxoval da criança é montado em "azul" ou "cor-de-rosa".

$\mathrm{Na}$ avaliação de Nicholson (1999), este processo deriva de uma tendência enraizada historicamente.

\begin{abstract}
A tendência a pensar em identidade sexual como algo dado, básico e comum entre as culturas é muito poderosa. Enfraquecer o domínio dessa tendência sobre nos mesmas exige uma noção sobre seu contexto histórico. Na medida em que podemos ver a identidade sexual como enraizada historicamente, como produto de um sistema de crenças especifico de sociedades modernas ocidentais, podemos também apreciar a diversidade profunda das formas pelas quais a distinção masculino/feminino pôde e pode ser entendida (NICHOLSON, 1999, p. 7).
\end{abstract}

Deste modo, verifica-se que o sistema binário do gênero (feminino ou masculino) revela-se em uma ideia nefanda que procura normatizar e normalizar os corpos. Para Bento (2006, p. 87) pode-se pensar o gênero como "uma sofisticada tecnologia social heteronormativa, operacionalizada pelas instituições médicas, linguísticas, domésticas, escolares e que produzem constantemente corpos-homens e corpos-mulheres”.

Assim, este trabalho visa analisar a sexualidade desde o contexto binário "normal/anormal", transitando pela homossexualidade e os gêneros sexuais, destacando a 
busca pelo reconhecimento dos homossexuais através dos movimentos sociais realizados, principalmente no Século XX, com a conquista de direitos através de mobilizações e pela

${ }^{1}$ É um termo relativamente recente e que designa um pensamento segundo o qual todas as pessoas são heterossexuais até provarem o contrario. Disponível http://www.dicionarioinformal.com.br/heterossexismo/. ${ }^{2}$ A matriz heteronormativa nomeia dois sexos distintos, masculino e feminino, como se fossem naturais e a partir daí cria categorias que sempre delimitam sujeitos inteligíveis e excluindo outros. Conforme Butler (2003, s./p.) "A heteronormatividade excluiu dos padrões socialmente aceitáveis tudo o que é relacionado à sexualidade não heterossexual e às experiências de gênero não binárias, varrendo-as para um campo de pessoas perigosas e aquém daquelas que seguem os padrões da heteronormatividade compulsória".

publicização dos temas através dos grupos homossexuais organizados no Brasil que, direta ou indiretamente, pautaram a mídia, foram reconhecidos no judiciário e sensibilizaram o poder público ${ }^{3}$.

\section{SEXUALIDADE: O QUE É NORMAL E ANORMAL?}

Vivemos em uma sociedade em que a sexualidade "normal" é a heterossexual e, desta forma, constitui-se um padrão heteronormativo de mundo, onde há uma cultura que busca condicionar determinados comportamentos que visam à heterossexualidade e, deste modo, todas as outras orientações sexuais são vistas como anormais, desviantes, problemáticas ou até mesmo colossais, sendo, na melhor das hipóteses, entendidas como “diferentes" (WELZER-LANG, 2001).

Em relação a "normal”, Bento (2008, p. 178-179) refere que, segundo o discurso heteronormativo, desde o nascimento as pessoas possuem uma única possibilidade para construir sua sexualidade e gênero, ou seja, na "perspectiva binária, o masculino e feminino seriam a expressão ou a formulação cultural da diferença natural dos sexos". Ainda, neste sentido, descreve a autora:

Nascemos e somos apresentados a uma possibilidade de construirmos sentidos identitários para nossas sexualidades e gêneros. Há um controle minucioso na produção da heterossexualidade. E como as práticas sexuais se dão na esfera do privado, será através do gênero que se tentará controlar e produzir a heterossexualidade. Se meninos gostam de brincar de casinha, logo surgirá um olhara atento para alertar os pais que seu/sua filho/a tem comportamentos "estranhos". Daí o perigo que a transexualidade representa para as normas de gênero, à medida que reivindica o gênero em discordância com o corpo-sexuado (BENTO, 2008, p. 41). 
Para Weeks (2000) a "institucionalização da heterossexualidade" se deu nos séculos XIX e XX, momento em que se estabeleceu o que eram "masculinidade" e "feminilidade" normais, bem como se catalogou uma infinita variedade de práticas sexuais.

\begin{abstract}
A tentativa de definir mais rigorosamente as características do "pervertido" (termos descritivos tais como "sado-masoquismo" e "travestismo" para as atividades relacionadas com sexo emergiram no fim do século XIX, ao lado de termos como "homossexualidade" e "heterossexualidade") foi um elemento importante naquilo que estou chamando de institucionalização de heterossexualidade nos séculos XIX e XX. Essa definição era, em parte, um empreendimento sexológico. A sexologia tomou a si duas tarefas distintas ao final do século XIX. Em primeiro
\end{abstract}

\footnotetext{
${ }^{3}$ Não é objetivo deste estudo ingressar nas manifestações sociais de Junho de 2013. Antes disso, analisar criticamente os movimentos sociais dos homossexuais até então, visando abordar a importância desses movimentos na consecução/reconhecimento de espaço, participação e, principalmente, direitos humanos correlatos.
}

\begin{abstract}
lugar, tentou definir as características básicas do que constitui a masculinidade e a feminilidade normais, vistas como características distintas dos homens e das mulheres biológicos. Em segundo lugar, ao catalogar a infinita variedade de práticas sexuais, ela produziu uma hierarquia na qual o anormal e o normal poderiam ser distinguidos. Para a maioria dos pioneiros, os dois empreendimentos estavam intimamente ligados: a escolha do objeto heterossexual estava intimamente ligada ao intercurso genital. Outras atividades sexuais ou eram aceitas com prazeres preliminares ou eram condenadas como aberrações (WEEKS, 2000, p. 63, grifos nossos).
\end{abstract}

Portanto, a partir dessa concepção procura-se descrever como surgiram as discussões a respeito da homossexualidade e porque alguns autores a consideram como o terceiro gênero.

\title{
3 HOMOSSEXUALIDADE COMO “TERCEIRO GÊNERO"
}

A divisão das pessoas em homens e mulheres, homossexuais e heterossexuais, era algo teoricamente impossível e, em termos sociais, algo impraticável anteriormente à diferenciação dos sexos. Assim, surge a concepção dos homossexuais e heterossexuais como uma consequência político-teórica das normas feitas à mulher e ao homem no twosex model. Enquanto no one-sex-model a mulher era um homem invertido e inferior, no two-sex-model ela passa a ser considerada o inverso complementar do homem. Em contrapartida a essa mudança, o homossexual passou a ser o invertido e "sua inversão será 
vista como perversão, por quanto antinatural" (COSTA, 1995, p. 128) e até mesmo considerada como uma doença.

Quanto à historicidade da homossexualidade Weeks (2000, p. 66) descreve que “antes do século XIX a 'homossexualidade' existia, mas o/a 'homossexual' não”. O autor ainda refere que (p. 66):

[...] embora a homossexualidade tenha existido em todos os tipos de sociedade, em todos os tempos, e tenha sido, sob diversas formas, aceita ou rejeitada, como parte dos costumes e dos hábitos sociais dessas sociedades, somente a partir do século XIX e nas sociedades industrializadas ocidentais, é que se desenvolveu uma categoria homossexual distintiva e uma identidade a ela associada. A emergência, na Alemanha e em outros países da Europa Central e Ocidental, tal como a Grã-Bretanha, nos anos de 1870 e 1880, de descritos sobre homossexuais - e, mais crucialmente, por homossexuais foi um estágio importante nessa mudança [...].

Segundo Fry e MacRae (1985), os primeiros textos escritos por médicos sobre relações sexuais entre pessoas do mesmo sexo vieram a público entre 1860 e 1869, quando as palavras: "homossexual" e "uranista" 4 foram concebidas como sendo sinônimas. Conforme os

\footnotetext{
${ }^{4}$ Pessoa que sente atração física ou amorosa por outras pessoas do mesmo sexo. Disponível em: http://www.dicio.com.br/uranista/. Acesso em: 12 ago. 2015.
}

autores, em 1869 o médico húngaro Karoly Maria Benkert usou, pela primeira vez, o termo "homossexual", mas antes disso, ainda no ano de 1860, o médico alemão Karl Heinrich Ulrichs passou a utilizar a palavra "uranista" 5 ". Os autores descrevem, ainda, a explicação de Ulrichs sobre a formação da homossexualidade:

\begin{abstract}
O embrião humano, acreditava Ulrichs, no inicio não é nem masculino nem feminino, mas depois de alguns meses a diferenciação ocorre. No caso dos uranistas, os órgãos genitais vão numa direção e o cérebro noutra. Assim se produz "uma alma feminina encapsulada num corpo masculino" e vice-versa. Ulrichs depois desenvolveu uma classificação complexa de "tipos homossexuais" entre os quais o Mannling, que é totalmente masculino em aparência e personalidade, o Weibling, que é efeminado, o Zwischen-urning, que é um tipo intermediário. Os primeiros dois termos equivalem aos termos "homossexual ativo" e "homossexual passivo" que a medicina vai desenvolver mais tarde e que são usados correntemente até hoje (FRY; MACRAE, 1985, p. $62-63$, grifo nosso).
\end{abstract}

Para Weeks (2000) a afirmação do termo heterossexualidade apenas foi possível devido à necessidade de definição da homossexualidade, dessa forma, passando a assumir 
uma descrição médico-moral no século XIX, empreendida pelo alemão Kraft-Ebing como forma de especificar as identidades sexuais justamente no que se referia a seus tipos e formas.

Franco (2009), por sua vez, explica que após sua qualificação, a homossexualidade passou a referir-se a um tipo de pessoa distinta, a uma espécie, tomando-se um termo oposto e crucial em relação à heterossexualidade após a consolidação das sociedades industrializadas ocidentais, o que não acontecia antes do século XIX. Dessa forma, na segunda metade do século XX, os processos de industrialização, urbanização e desenvolvimento socioeconômico foram representativos na estruturação de identidades gays e lésbicas em diversas sociedades ocidentais, inclusive na brasileira.

Neste sentido, Weeks (2000) refere-se à importância das comunidades lésbicas e gays na sociedade civil de países ocidentais:

\begin{abstract}
Na medida em que a sociedade civil nos países ocidentais se torna mais complexa, mais diferenciada, mais auto-confiante [sic], as comunidades lésbica e gay têm se tornado uma parte importante desta sociedade. Cada vez mais, a homossexualidade se torna uma opção, ou uma escolha, a qual os indivíduos podem seguir de um modo que era impossível numa sociedade mais hierárquica e monolítica. A existência de um modo de vida gay dá oportunidade para as pessoas explorarem suas necessidades e desejos, sob formas que eram algumas vezes literalmente inimagináveis até bem pouco tempo. É por isso, obviamente, que a homossexualidade é vista, frequentemente, como uma ameaça para aqueles ligados ao status quo moral, estejam eles situados à esquerda ou à direita do espectro político. A existência de identidades lésbica e gays positivas simboliza a
\end{abstract}

\footnotetext{
5 Complementando a nota anterior, o neologismo "uranista" foi inventado em homenagem à musa Urânia que, no mito contado por Platão, seria a inspiradora do amor entre pessoas do mesmo sexo (FLY; MACRAE, 1985).
}

pluralização cada vez mais crescente da vida social e a expansão da escolha individual que essa oferece (WEEKS, 2000, p. 69-70, grifos nossos).

Deste modo, destaca-se a importância de abordarmos também o processo da construção social do movimento homossexual e seu reflexo na construção da imagem dos direitos e das lutas para os homossexuais na sua abrangência histórico-social, da metade do século XX em diante. 


\section{OS HOMOSSEXUAIS E A BUSCA PELO RECONHECIMENTO: A IMPORTÂNCIA DOS MOVIMENTOS SOCIAIS}

Ataíde (2013) refere que os movimentos identitários, pós década de 1960, também conhecidos como "novos movimentos sociais", têm proposto a problematização das relações de poder que giram em torno das produções sociais das identidades e das diferenças, buscando, basicamente, o respeito aos direitos fundamentais e à liberdade dos indivíduos. Todavia, deve-se perceber que estas relações identidades/diferenças são fortemente marcadas por relações de poder e, neste sentido, a afirmação das identidades e o balizamento das diferenças implicam sempre em operações de "incluir" e de "excluir", de "classificar" e/ou "hierarquizar".

MacRae (1997) relata que em várias partes do mundo, incluindo o Brasil, a década de 1970 foi marcada pelo surgimento de uma política baseada no conceito de identidades pessoais ${ }^{6}$. Abandonando as tradicionais organizações sociais com problemas específicos que afetavam determinados grupos.

Dotados de um caráter marcadamente expressivo, esses movimentos desenvolviam formas de convivência e de participação vividas como positivas em si mesmas, calcadas num sentimento de igualdade e identificação entre todos os seus membros. Certas carências ou particularidades de estilo de vida foram eleitas como a base de novas identidades sociais, muitas vezes de caráter totalizante (MACRAE, 1997, p. 237).

\footnotetext{
${ }^{6}$ Para estudiosos do movimento LGBT, como Facchini (2005), Fry e MacRae (1985), entre outros, o marco da organização homossexual foi o fato ocorrido em Stonewall no ano de 1969. Stonewall Inn era um pequeno bar localizado na Rua Christopher, do Greenwich Village, em Nova Iorque. O bar era frequentado principalmente por homossexuais pertencentes à comunidade gay nova-iorquina. Uma espécie de "gueto", onde a vida gay acontecia apesar das perseguições policiais. O referido bar era constantemente vítima de batidas e os homossexuais sempre fugiam com medo da publicidade de suas identidades. O bar pagava propina aos policiais em troca de "segurança". Entretanto, na noite de 27 de junho de 1969 foi diferente, pois os frequentadores resolveram permanecer e enfrentar os policiais. Este combate permaneceu até o dia seguinte, 28 de junho de

1969, e ficou conhecido como a "Rebelião de Stonewall". Por este motivo, o dia 28 de junho foi consagrado como Dia Internacional do Orgulho Gay, símbolo de um novo momento da luta homossexual, marcada por visibilidade e enfrentamento, nem sempre violento, mas na defesa da garantia de seus direitos mais primários em várias partes do mundo (PASSAMANI; MAIA, 2011).
}

Exatamente neste período, fim da década de 70 (séc. XX) e início de 1980, quando a sociedade brasileira vivia num contexto de regime militar, que os movimentos sociais marcaram a história na busca não somente pela democracia, mas pela cidadania plena e pelos direitos civis. Segundo Molina (2011), essa visibilidade também foi construída pelos movimentos gays. 
As primeiras iniciativas do movimento homossexual no Brasil surgiram com a fundação do "Jornal Lampião da Esquina" no Rio de Janeiro no ano de 1978 e do grupo “SOMOS - Grupo de Afirmação Homossexual”, no ano de 1979. O intuito destes grupos era formar alianças com outras minorias. Neste sentido, a descrição de Fry e MacRae (1985, p.

21):

O Jornal Lampião, editado no Rio de Janeiro por jornalistas, intelectuais e artistas homossexuais que pretendiam originalmente lidar com a homossexualidade procurando forjar alianças com as demais "minorias", ou seja, os negros, as feministas, os índios e o movimento ecológico [...].

MacRae (1997) acrescenta que diante da grande repercussão que o Jornal Lampião de Esquina e o grupo "SOMOS" tiveram em todo o Brasil, logo surgiram outros grupos espalhados pelo país ${ }^{7}$, seguindo mais ou menos a mesma linha. Neste sentido, refere o autor:

Esses grupos aderiram ao novo esquema político que surgia, em parte importado dos Estados Unidos e da Europa, e procuravam valorizar a identidade homossexual, lutar contra a discriminação ou atentados contra os direitos humanos dos homossexuais. Chegaram até a promover uma grande passeata contra um delegado em São Paulo, o doutor Wilson Richetti, que estava promovendo uma "operação limpeza" no centro da cidade, prendendo e batendo em travestis e prostitutas. Buscavam alianças com o movimento feminista e o movimento negro, que eram identificados como sendo muito similares em sua estrutura e em várias reivindicações (MACRAE, 1997, p. 239).

Nos anos 1980 o Grupo Gay da Bahia - GGB inicia suas atividades, exercendo-as com influência muito grande neste período e, consequentemente, ajudando a fortalecer o ativismo na região. No ano seguinte, em 1981, o jornal Lampião encerra suas atividades, enquanto o GGB inicia uma campanha nacional para a despatologização ${ }^{8}$ da homossexualidade (FACCHINI, 2011).

De acordo com Molina (2011, p. 955) é nesse contexto que os grupos e as

\footnotetext{
${ }^{7}$ Entre estes outros grupos que surgiram estão o "Triângulo Rosa" e "Atobá" (Ambos do Rio de Janeiro, 1980), Grupo Gay da Bahia (criado em 1980, ainda existe sendo considerado um dos mais importantes), Grupo Dignidade (criado em 1992, no Paraná), entre vários outros (FACCHINI, 2011).

8 Despatologização da homossexualidade é a sua exclusão definitiva da classificação internacional de doenças (FACCHINI, 2011, s/p.).
} 
associações voltadas à homossexualidade se fortalecem perante a sociedade e ganham visibilidade aproximando o Movimento Gay do Estado Nacional, por meio de políticas públicas direcionadas a contenção do vírus HIV - AIDS, que atingi de forma intensa a comunidade homossexual masculina. A referida autora descreve ainda:

\begin{abstract}
A epidemia obrigou a sociedade a discutir sexualidade. Independentemente da forma como foi orientada a temática, ela passou a estar presente nas agendas e a ser preocupação para familiares, escolares e estatais. O surgimento da Aids abriu espaço para a visibilidade homossexual, ainda que se tenham inicialmente refreado as tentativas de mobilizar setores do movimento. A doença foi também uma das principais responsáveis pela força com que esse movimento (re)emergiu na década de 90 do séc. passado (MOLINA, 2011, p. 956).
\end{abstract}

O movimento homossexual foi expandindo para todo o Brasil, através de diversos grupos que foram surgindo no decorrer dos anos. Diante desta expansão, no ano de 1995, foi fundada a primeira e maior rede de organizações LGBT brasileiras, a ABGLT Associação Brasileira de Gays, Lésbica e Travestis, que, conforme Facchini (2011, s/p.) "reúne cerca de 200 organizações espalhadas por todo o Brasil, sendo considerada a maior rede LGBT na América Latina".

Nos anos de 1996 e 1997, o Rio de Janeiro e São Paulo, respectivamente, lançam suas primeiras Paradas do Orgulho Gay, com mais destaque na imprensa carioca. Nos anos seguintes as "Paradas" aumentaram consideravelmente o número de participantes (ARAÚJO, 2009, s./p.). Santos (2007) assinala que no ano de 1996 houve uma tentativa de organização de uma "parada gay” em São Paulo, mas foi frustrada ${ }^{9}$ e, somente no ano seguinte, em 1997 que realmente o evento aconteceu e, devido a grande adesão de participantes, passou a acontecer anualmente e se tornou uma das principais formas de manifestação do movimento homossexual no Brasil:

Em 1997, o IX Encontro Brasileiro de Gays, Lésbicas e Travestis e o II Encontro Brasileiro de Gays, Lésbicas e Travestis que Trabalham com Aids (EBGLT-Aids) ocorreram mais uma vez em São Paulo, com a participação de 52 grupos tanto da militância GLT (Gays, Lésbicas e Travestis) como de ONGAids e simpatizantes. Havia muito conflito entre seus organizadores, sendo que vários grupos foram excluídos da comissão de organização. Apesar disso, foi neste ano que os grupos de São Paulo organizaram a Parada do Orgulho GLT, que se tornou símbolo do movimento homossexual no Brasil. Mesmo depois de uma primeira tentativa

\footnotetext{
${ }^{9}$ Segundo Trindade (2011), apenas alguns atuantes militantes, algumas drags, conhecidas por suas performances nas boates gays da cidade e outras personalidades da cena gay, além, vale dizer, dos punks que se solidarizavam com as reivindicações dos gays e lésbicas, se fizeram presentes na Praça Roosevelt no dia marcado para a primeira "parada gay" em São Paulo. O autor relata, ainda, que Sobre a (pequena)
} 
quantidade de pessoas que compareceram ao evento, um jornalista de São Paulo sugeria que o homossexual brasileiro preferia o anonimato de "seus armários" à exposição pública de sua orientação sexual (TRINDADE, 2011, p. 77).

frustrada em 1996, em 28 de junho de 1997, aproximadamente duas mil pessoas seguiram pela Avenida Paulista com o intuito de atrair a atenção da sociedade e dar visibilidade pública às reivindicações dos homossexuais. A Parada do Orgulho GLBT passou a acontecer todos os anos, tornando-se parte integrante do calendário oficial da cidade. Ao reunir aproximadamente um milhão e meio de pessoas, esse evento passou a ser uma das principais formas de o movimento homossexual afirmar sua existência como sujeito político (SANTOS, 2007, p. 127).

Diante das proporções que alcançou a Parada do Orgulho GLBT em São Paulo, outras cidades brasileiras passaram a realizar eventos semelhantes com o objetivo de chamar a atenção para as reivindicações dos grupos GLBT, dentre elas: Belo Horizonte (Parada do Orgulho LGBT de Belo Horizonte), Curitiba (Parada da Diversidade LGBT), Salvador (Parda Gay da Bahia), Florianópolis (Parada da Diversidade), Fortaleza (Parada Gay de Fortaleza), Campo Grande (Parada da Diversidade de Campo Grande), Brasília (Marcha Nacional contra a Homofobia), Porto Alegre (Parada Gay) etc. (MASSINI, 2012).

\subsection{As manifestações sociais e a inclusividade queer}

A teoria queer aparece como uma forma de chamar a atenção para o fato de como uma política de identidade pode se tornar cúmplice do sistema contra o qual ela pretende se insurgir e para isto os teóricos e as teóricas queer sugerem uma teoria e uma política pós-identitária, utilizando-se como foco principal a crítica à oposição heterossexual/homossexual, compreendida como a categoria central que organiza as práticas sociais, o conhecimento e as relações entre os sujeitos, neste sentido a

\footnotetext{
teoria queer surge da cultura intelectual gay e lésbica a partir da metade dos anos 1980, inspirada especialmente pela crítica ao modelo de definição das identidades sexuais e de gênero como estáveis e fixas (heteronormatividade). Ainda, procura concentrar-se menos às identidades e mais nas práticas sexuais, incluindo, dessa forma, tanto travestis e drag queens, quanto sadomasoquistas etc. (FURLANI, 2009, p. 313).
}

A expressão "queer" é uma apropriação de um termo utilizado para ofender e insultar; em português, poderia se aproximar das palavras "bicha" ou "veado", constantemente utilizadas como formas linguísticas e discursivas de afrontar gays. Esse 
movimento é caracterizado principalmente pela indefinição e instabilidade, e está mais preocupado em perturbar estruturas definidoras e fixas do que reconstruí-las (SALIH, 2012).

Entretanto, nas palavras de Louro (2004, p. 7) ainda que o termo queer apresente uma sua carga de estranheza e de deboche, é assumido pelo movimento homossexual como

uma forma de protesto contra a normalização e à estabilidade das propostas pela política de identidade e, deste modo, "queer passa a ser, também o sujeito da sexualidade desviante - bissexuais, homossexuais, transexuais, travestis, drag queens". Ainda segundo a autora "a teoria queer permite pensar a ambiguidade, a multiplicidade e a fluidez das identidades sexuais e de gênero, mas, além disso, também sugere novas formas de pensar a cultura, o conhecimento, o poder e a educação" (2004, p. 47).

Neste sentido, através dos movimentos sociais como as "paradas gays" e outros $^{10}$, os homossexuais buscam ser reconhecidos como sujeitos de direitos e mostrar que outras formas de identidade sexual e de gênero são possíveis, incluindo-se aqui, além dos gays e lésbicas, os travestis, transexuais e transgêneros.

\subsection{As conquistas dos homossexuais}

O nascimento do movimento homossexual foi marcado, na sua essência, pela busca de mudanças, ou mesmo a revolução de uma realidade hostil em relação a certos grupos (homossexuais, negros, mulheres etc.) ou classes sociais, objetivando a luta por um ideal, questionando uma determinada realidade que apresenta impeditivos para a realização das aspirações deste movimento. Facchini (2011) ressalta a importância do surgimento do movimento homossexual no Brasil:

[...] o surgimento do movimento homossexual indica a aspiração a reivindicar direitos universais e civis plenos, por meio de ações políticas que não se restringiam ao "gueto", mas que se voltava para a sociedade de modo mais amplo. Com antecedentes em mobilizações acontecidas em outros países desde fins da década de 1960, e a partir de redes de sociabilidade estabelecidas nas grandes cidades, os primeiros grupos militantes homossexuais surgiram no Brasil no final dos anos

${ }^{10}$ Exemplo dessas outras formas de manifestação são as torcidas homossexuais organizadas. Conforme Soares

(2013, s./p.), que explorou "11 movimentos anti-homofobia no futebol brasileiro", em 1977 a Coligay gremista "foi a primeira torcida assumidamente gay do país. Criado durante a Ditadura Militar em um 
contexto em que o preconceito era ainda mais forte nos estádios, o grupo inspirou a criação, dois anos depois, da Fla-Gay, organizada do Flamengo" (grifos da autora). Destaca a jornalista que "Passadas quase quatro décadas desde as iniciativas que lançaram luz sobre um dos maiores tabus do mundo do futebol, ainda parece haver um longo caminho rumo à tolerância nos estádios, onde a homofobia é gritada a plenos pulmões. Tentando contribuir para uma mudança nesse cenário e ecoando as pioneiras Coligay e Fla-gay, em abril de 2013 uma socióloga mineira resolveu criar a página Galo Queer, movimento dos torcedores do Atlético-MG contra a homofobia e o sexismo nos estádios. Diferentemente das iniciativas da década de 1970, a ideia não é reunir apenas homossexuais, mas todos que defendem a tolerância. A iniciativa não revolucionou o contexto histórico de preconceito e machismo, mas ajudou a colocar o tema em debate. Assim como o "Galo é amor, não é intolerância", como defende a página, o futebol também pode caminhar para ampliar o respeito à diversidade. Na Inglaterra parece haver esperança de uma mudança: uma pesquisa da Universidade de Staffordshire, que contou com a participação de 3,5 mil pessoas (entre torcedores, jogadores, árbitros e técnicos), descobriu que $\mathbf{9 3 \%}$ dos entrevistados condenam o preconceito aos gays no esporte e $60 \%$ disseram que gostariam de ver jogadores assumindo sua homossexualidade."

1970, no contexto da "abertura" política que anunciava o final da ditadura militar (FACCHINI, 2011, s/p.).

Nota-se que este movimento foi originado a partir de manifestações de grupos de pessoas que até então eram (ao menos assim se sentiam) invisíveis e que se uniram em torno da defesa de seus direitos, batalhando por visibilidade, por reconhecimento. Um marco nas conquistas dos direitos almejados pelo movimento homossexual foi à exclusão definitiva da homossexualidade da classificação internacional de doenças, fato que aconteceu nos anos de 1985 e 1994 quando, respectivamente, o Conselho Federal de Medicina e a Organização Mundial de Saúde excluíram definitivamente da classificação internacional de doenças a homossexualidade, que até aquele momento era considerada um "desvio e transtorno sexual".

Vários foram os avanços realizados no Brasil em relação à conquista de direitos aos homossexuais. Atualmente encontram-se regularizados diversos direitos tidos como essenciais para a garantia de uma vida digna aos cidadãos homossexuais, quais sejam: (a) a possibilidade de realização da cirurgia de mudança de sexo através do Sistema único de Saúde

$-\operatorname{SUS}^{11}$; (b) a adoção por casais homossexuais ${ }^{12}$; (c) direito ao uso do nome social ${ }^{13}$; (d) inclusão do(a) companheiro(a) na declaração do $\operatorname{IR}^{14}$; (e) reconhecimento da União Estável de casais homossexuais ${ }^{15}$; (f) licença-maternidade a pai adotivo gay ${ }^{16}$; (g) o casamento civil gay ${ }^{17}$, entre outros.

As conquistas por esses direitos foram possíveis, sobretudo, na mobilização e na publicização dos temas através dos vários movimentos realizados pelos grupos homossexuais organizados no Brasil. Pautaram, direta ou indiretamente, a mídia, o judiciário e o poder público, embora ainda se saiba que há necessidade de 
reconhecimentos outros, principalmente de cunho social e moral, porquanto a sociedade ainda é pautada por hierarquização e esteriótipos.

\section{CONSIDERAÇÕES FINAIS}

\footnotetext{
${ }^{11}$ Portaria $\mathrm{n}^{\mathrm{o}} 457$, de 19 de agosto de 2008 e Portaria $\mathrm{n}^{\mathrm{o}} 2.803$, de 19 de novembro de 2013, ambas do Ministério da Saúde.

${ }^{12}$ Supremo Tribunal Federal reconheceu a adoção de criança por casal homoafetivo com base na decisão do plenário do Supremo, que reconheceu, em 2011, por unanimidade, a união estável de parceiros do mesmo sexo (PORTALBRASIL, 2015).

${ }^{13}$ O Decreto $n^{\text {o }} 49.122$ de 17 de maio de 2012, instituiu a Carteira de Nome Social para Travestis e Transexuais no Estado do Rio Grande do Sul.

${ }_{15}^{14}$ Conforme Parecer no 1503/2010 da Procuradoria-Geral da Fazenda Nacional (PGFN)

${ }^{15}$ No julgamento da Ação Direta de Inconstitucionalidade (ADI) 4.277 e a Arguição de Descumprimento de Preceito Fundamental (ADPF) 132, no ano de 2011, os ministros do Supremo Tribunal Federal (STF), reconheceram a união estável para casais do mesmo sexo.

${ }_{17}^{16}$ Previsão no art. 71-A da Lei no ${ }^{\circ} 12.783$ de 24 de outubro de 2013.

${ }^{17}$ Resolução n. 175, de 14 de maio de 2013 do Conselho Nacional de Justiça.
}

Diante deste estudo verificou-se que a sexualidade não é uma categoria fixa, mas que sofre uma constante transformação em razão das influências culturais da sociedade em que se apresenta. Da mesma forma, observou-se que o corpo bissexuado nem sempre foi considerado como "normal". Houve períodos em que os corpos femininos eram considerados corpos masculinos "invertidos" e somente no séc. XIX que passamos a ter a noção de corpo bissexuado, com definições específicas para feminino e masculino, construindo-se um padrão heteronormativo de mundo. Tudo e todos que se apresentavam diferentes desse padrão eram considerados anormais, desviantes e problemáticos, sendo excluídos.

Deste modo, os considerados "anormais", neste caso os homossexuais, pois estavam fora dos padrões heterossexuais estabelecidos como "habituais", passam a se reunir contra estas discriminações, surgindo os movimentos sociais homossexuais.

Assim, pontuou-se que direitos já foram garantidos. Outros, como a criminalização (ou não) da homofobia, merecem ser discutidos pela sociedade brasileira. Já os movimentos sociais homossexuais não podem parar ou ficar estanques em determinados assuntos. No entanto, questiona-se se devem eles realmente buscar uma afirmação identitária?

De acordo com Bauman (2005, p. 12), em uma "sociedade que tornou incertas e transitórias as identidades sociais, culturais e sexuais", as tentativas "de 'solidificar' o que 
se tornou líquido por meio de uma política de identidade levaria inevitavelmente o pensamento crítico a um beco sem saída".

O pensamento do sociólogo tem fundamento e a coerência deve ser sopesada pelos movimentos sociais de homossexuais, pois que a afirmação identitária pode e deverá continuar a excluir. O reconhecimento por direitos não precisa acarretar o reconhecimento identitário como "gay", como "lésbica", como "travesti” etc., mas os avanços nos espaços de discussão e reconhecimento são extremamente importantes.

Finalmente, a garantia legal de direitos aos homossexuais deve ser ponderada para que eventuais definições legais não venham a excluir determinadas relações, afetivas ou não, de seu alcance (RODRIGUEZ, 2008, p. 110-111), evitando-se que os que estão abrangidos pela proteção jurídica não defendam essas fronteiras e posição já alcançada "contra elementos indesejados", ao que se poderiam definir como eventuais efeitos perversos da regulação jurídica não socialmente contextualizada.

\section{REFERÊNCIAS}

ARAÚJO, Ana Claudia Condeixa. Ruas e bancas coloridas: os discursos da imprensa sobre as identidades homossexuais nas Paradas LGBT do Rio de Janeiro e de São Paulo. Revista ComUnigranrio, v. 01, p. 01-19, 2009.

ATAÍDE, Marlene Almeida de. Os movimentos sociais dos homossexuais na história: uma questão em análise. Seminário Internacional Enlaçando Sexualidades, Universidade do Estado da Bahia - Salvador, 2013.

BAUMAN, Zygmunt. Identidade. Rio de Janeiro: Zahar, 2005.

BENTO, Berenice. A reinvenção do corpo. Sexualidade e gênero na experiência transexual.

- Rio de Janeiro: Gramond, 2006.

O que é transexualidade. - São Paulo: Brasiliense, 2008.

BUTLER, Judith. Problemas de gênero: Feminismo e subversão de identidade. Rio de

Janeiro: Civilização Brasileira, 2003. 
Corpos que pensam: sobre os limites discursivos do "sexo". In: LOURO, Guacira (org). O corpo educado: pedagogias da sexualidade. Belo Horizonte: Autêntica, 2010.

CÂMARA DOS DEPUTADOS. Legislação Informatizada - Dados da Norma. Lei $\mathbf{n}^{\mathbf{0}}$ 12.783, de 11 de janeiro de 2013. Disponível em: <http://www2.camara.leg.br/legin/fed/lei/2013/lei-12783-11-janeiro-2013-775059-normapl.html >. Acesso em: 14 ago. 2015.

CONSELHO NACIONAL DE JUSTIÇA. Resolução $\mathbf{n}^{\mathbf{0}} \mathbf{1 7 5}$, de 14 de maio de 2013. Dispõe sobre a habilitação, celebração de casamento civil, ou de conversão de união estável em

casamento, entre pessoas de mesmo sexo. Disponível em: <http:// www.cnj.jus.br/files/atos_administrativos/resoluo-n175-14-05-2013-presidncia.pdf>.

Acesso em: 10 ago. 2015.

COSTA, Jurandir Freire. A Face e o verso: estudos sobre o homoerotismo, 2. São Paulo: Escuta, 1995.

ESTADO DO RIO GRANDE DO SUL - Assembleia Legislativa. Gabinete de Consultoria Legislativa. Decreto $\mathbf{n}^{\mathbf{0}}$ 49.122, de 17 de maio de 2012. Disponível em: <http://www.direitohomoafetivo.com.br/anexos/normatizacao/92__016b5a9c5e4a7ede52f bac dbe4d3ed68.pdf>. Acesso em: 14 ago. 2015.

FACCHINI, Regina. Sopa de letrinhas? O movimento homossexual e a produção de identidades coletivas nos anos de 1990. Rio de Janeiro, Garamond, 2005.

Histórico da luta de LGBT no Brasil. 2011. Disponível em:

<http://www.crpsp.org.br/portal/comunicacao/cadernos_tematicos/11/frames/fr_historico. asp x>. Acesso em: 10 ago. 2015.

FRY, Peter; MACRAE Edward. O que é homossexualidade. São Paulo: Abril Cultural Brasiliense, 1985.

FRANCO, Neil. A diversidade entra na escola: histórias de professores e professoras que transitam pelas fronteiras das sexualidades e do gênero. (Dissertação) - Universidade de Uberlândia, Uberlândia, 2009.

FURLANI, Jimena. Direitos Humanos, Direitos Sexuais e Pedagogia Queer: o que essas abordagens têm a dizer à Educação Sexual? In: Rogério Junqueira (Org.). Diversidade sexual

na educação: problematizações sobre a homofobia nas escolas. Brasília: Ministério da Educação/UNESCO, p. 293-323, 2009.

LOURO, Guacira Lopes. Teoria queer: uma política pós-identitária para a educação.

Florianópolis: Estudos Feministas, v. 9, n. 2, 2001. 
O corpo estranho. Ensaios sobre sexualidade e teoria queer. Belo

Horizo

nte:

Autêntica, 2004.

MACRAE, Edward J. B. N. Movimentos Sociais e os direitos de Cidadania dos Homossexuais. In: Angela Araujo. (Org.). Trabalho, Cultura e Cidadania. São Paulo: Scritta, p. 237-245, 1997.

MASSINI, Érica. Conheça as mais importantes Paradas LGBT e outros eventos deste gênero no mundo. Blog 1A, 03/09/2012. Disponível em: <http://amadeus1a.com.br/conheca-as-mais-importantes-paradas-lgbt-e-outros-eventosdeste-genero-no-mundo/>. Acesso em: 10 ago. 2014.

MINISTÉRIO DA SAÚDE. Portaria no 457, de 19 de agosto 2008. Disponível em: < http://bvsms.saude.gov.br/bvs/saudelegis/sas/2008/prt0457_19_08_2008.html>. Acesso em: 14 ago. 2015.

Portaria $\mathbf{n}^{\mathbf{0}}$ 2803, de 19 de novembro 2013. Disponível em: <http://bvsms.saude.gov.br/bvs/saudelegis/gm/2013/prt2803_19_11_2013.html>. Acesso em: 14 ago. 2015.

MOLINA, Luana. Pagano Peres. A homossexualidade e a historiografia e trajetória do movimento homossexual. Londrina: Antíteses, v. 4, p. 949-962, 2011.

NICHOLSON, Linda. Interpretando o gênero. Tradução Luiz Felipe Guinardes Soares. Revisão técnica Claudia de Lima Costa. Cornell Univesity Press, 1999.

PASSAMANI, Guilherme Rodrigues; MAIA, Lenine Ribas. Um herói gay: uma análise sobre

homofobia, militância e moralidade a partir de MILK - A Voz da Igualdade. In: Guilherme Rodrigues Passamani. (Org.). Ciclo de Cinema: entre histórias, teorias e reflexões. II

Volume. Campo Grande: Editora da UFMS, v. II, p. 85-98, 2011.

PORTAL BRASIL. STF reconhece adoção de criança por casal homoafetivo. 20/03/2015 11h59min. Disponível em: <http://www.brasil.gov.br/cidadania-ejustica/2015/03/ministra-do-stf-reconhece-adocao-de-crianca-por-casal-homoafetivo>.

Acesso em 14 ago. 2015.

PROCURADORIA-GERAL DA FAZENDA NACIONAL. Parecer $\mathbf{n}^{\mathbf{0}}$. 1503/2010. Disponível em: < http://www.pgfn.fazenda.gov.br/noticias/pgfn-divulga-parecerfavoravel-a-

inclusao-de-dependente-homoafetivo-para-efeitos-fiscais?searchterm=homoss $>$. Acesso em: 14 ago. 2015. 
RODRIGUEZ, José Rodrigo. FRANZ NEUMANN. O direito liberal para além de si mesmo.

In: Marcos Nobre. (Org.). Curso Livre de Teoria Critica. 2008, p. 97-116.

SALIH, Sara. Judith Butler e a Teoria Queer / Sara Salih. Tradução e notas Guacira Lopes Louro. - Belo Horizonte: Autêntica Editora, 2012.

SANTOS, Gustavo Gomes da Costa. Mobilização sexual e estado do Brasil: São Paulo (1978-2004). Revista Brasileira de Ciências Sociais, v.22, n.63, p.121-135, 2007.

SEDGWICK, Eve Kosofsky. A Epistemologia do Armário. In: Cadernos Pagu. Tradução de Plinio Dentzien. Campinas, Núcleo de Estudos de Gênero Pagu, 2007.

SOARES, Jessica. 11 movimentos anti-homofobia no futebol brasileiro. Super Interessante, 09/12/2013. Disponível em: <http://super.abril.com.br/blogs/superlistas/11movimentos-anti-homofobia-no-futebol-brasileiro/>. Acesso em: 12 ago. 2015.

SUPREMO TRIBUNAL FEDERAL. Ação Direta de Inconstitucionalidade 4.277

Distrito

Federal. Brasília, 2011. Disponível em: $<$ http://redir.stf.jus.br/paginadorpub/

paginador.jsp?docTP=AC\&docID=628635>. Acesso em: 14 ago. 2015.

TRINDADE, José Ronaldo. O mito da multidão: uma breve história da parada gay de São Paulo. Niterói: Revista Gênero, v. 11, n. 2, p. 73-97, set. 2011.

WEEKS, Jeffrey. O corpo e a sexualidade. In: LOURO, Guacira Lopes (Org.). O corpo educado: pedagogias da sexualidade. Belo Horizante: Autêntica, p. 35-83, 2000.

WELZER-LANG, Daniel. A construção do masculino: dominação das mulheres e homofobia. In: Estudos Feministas, Florianópolis, v.1, n. 2, p. 460-482, 2001. 